\title{
An unusual case of skin metastasis from a breast cancer mimicking a lymphangiosarcoma
}

\section{G S Nanayakkara ${ }^{1}$, D Weerasekara ${ }^{1}$, D H Beneragama ${ }^{2}$, P Samararathna ${ }^{2}$}

Ceylon Medical Journal 2014; 59: 68-69

Lymphangiosarcoma is a form of high grade cutaneous angiosarcoma commonly occurring in patients who have undergone mastectomy or irradiation for breast cancer. We report a case of cutaneous metastasis (CM) of ductal carcinoma of breast in the upper limb, clinically mimicking a cutaneous lymphangiosarcoma in a patient with chronic lymphoedema following ipsilateral mastectomy.

A 60-year old woman, following left modified radical mastectomy and axillary clearance for an invasive ductal carcinoma, ( $T_{2} N_{2} M_{0}$ stage) presented two years later with multiple enlarging ulcerative lesions with an everted edge and a necrotic centre in the ipsilateral lymphoedematous upper limb (Figure 1). She has been free of metastases before.

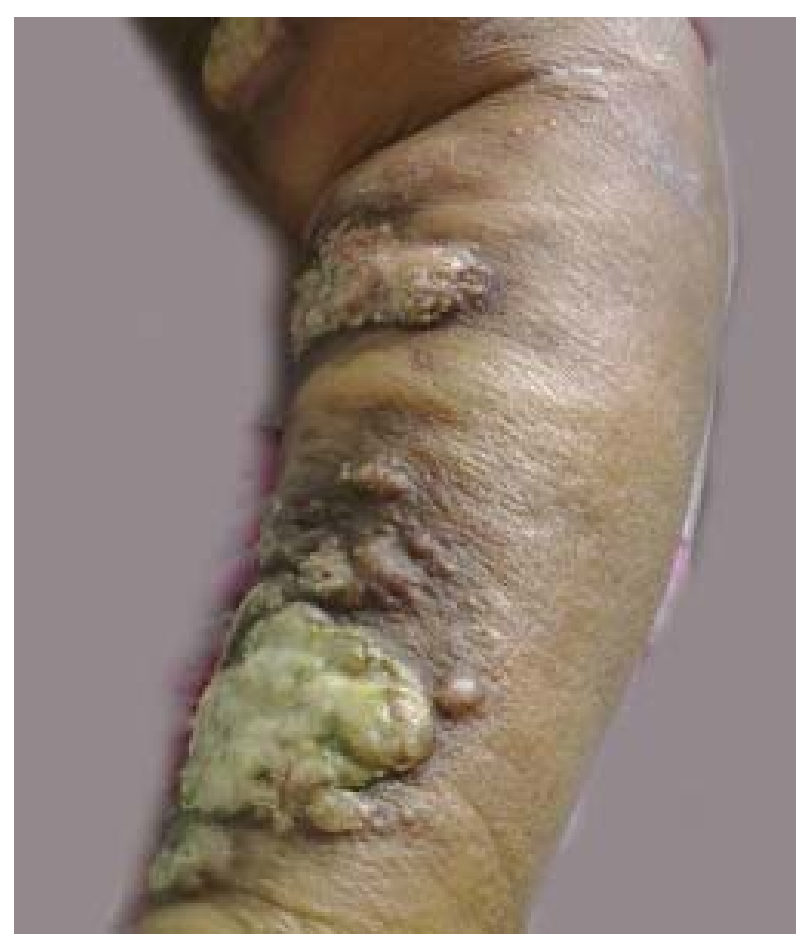

Figure 1. Left upper limb with ulcerative lesions.
Histology of the biopsied skin lesions showed a poorly differentiated duct carcinoma of the breast (negative for oestrogen receptors and positive for progesterone receptors and HER 2 receptors) (Figure 2 and 3).

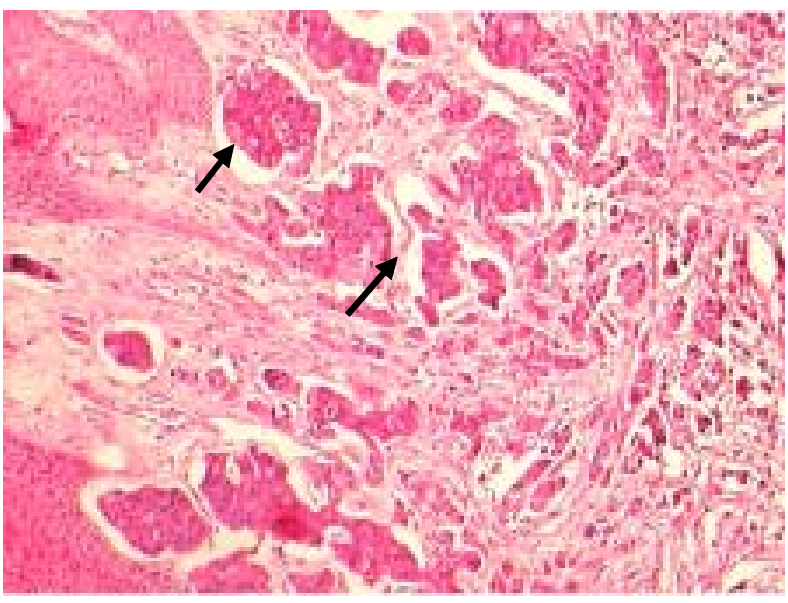

Figure 2. Islands of malignant cells within lymphatic spaces (arrows). Haematoxylin and eosin $\times 10$.

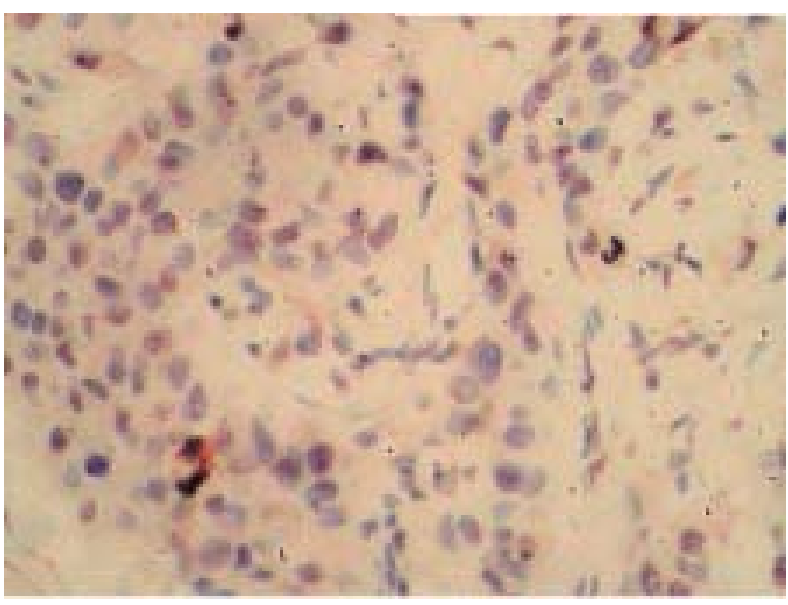

Figure 3. Negative ER staining - Immunohistochemistry $\times 40$.

${ }^{1}$ Surgical Unit and ${ }^{2}$ Department of Pathology, Faculty of Medical Sciences, University of Sri Jayawardenepura, Sri Lanka.

Correspondence: GSN, e-mail: <gayan_nanayakkara@yahoo.com>. Received 1 April 2013 and revised version accepted 29 November 2013. Competing interests: none declared. 
Stewart and Treves described the syndrome of post mastectomy lymphangiosarcoma [1]. A similar clinical entity, forearm CM of breast carcinoma, has been reported $[1,2,3]$.

$\mathrm{CM}$ of breast carcinoma in extremities is very rare, even though the overall incidence is approximately $25 \%$. The commonest presentation is multiple none ulcerated nodules and rarely telangiectatic, erysepeloid, 'en cuirasse' carcinomas, alopecia neoplastica and zosteriform type [3, 4]. We recommend a high degree of suspicion for metastatic lesions in patients presenting with ipsilateral, upper limb cutaneous lesions following breast cancer surgery, although lymphangiosarcoma is commoner.

\section{References}

1. Stewart FW, Treves N. Lymphangiosarcoma in postmastectomy lymphoedema. A report of six cases in elephantiasis chirurgica. Cancer 1948; 1: 64-81.

2. Schafler K, McKenzie CG, Salm R. Postmastectomy lymphangiosarcoma: a reappraisal of the concept - a critical review and report of an illustrative case. Histopathology 1979; 3: 131-52.

3. Frederick PF, Peter MM, Galen P. Extensive cutaneous metastatic breast carcinoma of the hand and upper extremity: a case report. Journal of Hand Surgery 2007; 32: 252-5.

4. Lookingbill DP, Spangler N, Sexton FM. Skin involvement as the presenting sign of internal carcinoma. A retrospective study of 7316 cancer patients. Journal of American Academy of Dermatology 1990; 22: 19-26.

\title{
An unusual presentation of a functioning solitary ectopic thyroid
}

\author{
J Thomas, G A Ghate, P N Shah
}

Ceylon Medical Journal 2014; 59: 69-70

A 14-year old female presented with a swelling in the left submandibular area, which had been present since birth. She had no pain associated with the swelling. On examination a smooth, firm non-tender, non-fluctuant swelling $3 \mathrm{~cm}$ x $2 \mathrm{~cm}$ was detected in the left submandibular region (Figure 1). The swelling was non pulsatile, and did not move with deglutition or protrusion of the tongue. It was non-fluctuant and transillumination test was negative. She had no other swelling in the neck nor was there any cognizant cervical lymphadenopathy. There were no systemic symptoms suggestive of any metabolic disorder. Fine needle aspiration cytology of the swelling revealed abundant thick and thin colloid, thyroid acinar follicles and scattered foamy macrophages. Ultrasonography revealed an ovoid hypo-echoic nodule, with regular contours, measuring $3.4 \times 2.2 \mathrm{~cm}$ in the left submandibular region and the thyroid gland was not visualised at its normal site. Scintigraphy with iodine-131, showed uptake of radiopharmaceuticals in the left submandibular region and no uptake in the normal anatomical site of the thyroid gland (Figure 2) [1]. Thyroid function tests conducted simultaneously revealed that she was euthyroid. In view of the fact that she was euthyroid and since the fine needle aspiration cytology revealed normal functioning thyroid tissue, surgery has been withheld and the patient is undergoing regular follow-up.

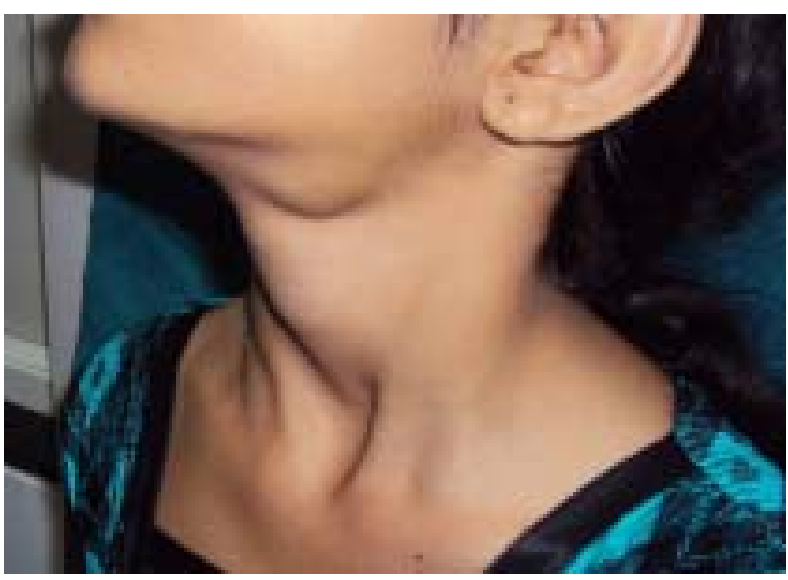

Figure 1.

Department of ENT and HNS, Padmashree Dr. D. Y. Patil Medical College, Pune, India.

Correspondence: JT, e-mail: <jaytees66@yahoo.com>. Received 7 November 2013 and revised version accepted 18 January 2014. Competing interests: none declared. 